\title{
N1 Stage Finding
}

National Cancer Institute

\section{Source}

National Cancer Institute. N1 Stage Finding. NCI Thesaurus. Code C48706.

A general term that refers to a TNM finding of cancer metastases usually in a limited number of regional lymph nodes. The definition of N1 TNM finding depends on the specific type of cancer that it refers to; for example, for breast cancer it refers to micrometastases or metastases in 1-3 axillary lymph nodes; for cutaneous melanoma it refers to metastasis in 1 regional lymph node; for colorectal cancer it refers to metastases in 1-3 regional lymph nodes; and for bladder cancer it refers to metastasis in 1 regional lymph node in the true pelvis. 